\title{
Active or Passive Pelvic Floor Exercise for Fourth Trimester Population, it Matters!
}

\begin{abstract}
Jui-Yuan Chen ${ }^{1}$, I-Fang Yang', Wei-Jiun Li $^{3}$, Lee-Wen Huang ${ }^{4}$, Jier-Zen Chang ${ }^{5}$, Kenneth Pan ${ }^{6}$, Cristiana Pan ${ }^{6}$ and Hun-Shan $\operatorname{Pan}^{7 *}$
\end{abstract}

${ }^{1}$ Department of Obstetrics and Gynecology, Shin Kong Wu Ho-Su Memorial Hospital, Taiwan

${ }^{2}$ Fu Jen Catholic University, Taiwan

${ }^{3}$ Department of Science, University of British Columbia, Canada

${ }^{4}$ Ranchlands Medical Center, Canada

${ }^{5}$ Department of Anesthesiology, Shin Kong Wu Ho-Su Memorial Hospital, Taiwan

${ }^{6}$ Wei-gong memorial hospital, Taiwan

${ }^{7}$ Department of General surgery, Shin Kong Wu Ho-Su Memorial Hospital, Taiwan

Submission: July 08, 2021; Published: July 14, 2021

*Corresponding author: Hun-Shan Pan, Department of General surgery, Shin Kong Wu Ho-Su Memorial Hospital, Taiwan

Keywords: Woman's urinary control abilities; Woman's pelvic floor muscles; Hormones; Genetics; Childbirth; Postpartum period; Patient global impression; Obstetric; Sphincter injury; Pregnancy; Sacrospinous ligament fixation; Pelvic surgeons; Gynecology; Urinary leakage; Pelvic organ prolapse

\section{Introduction}

Giving birth is extremely tough on the body and can change a woman's urinary control abilities. During pregnancy, the weight of the expanding uterus can weaken the strength of a woman's pelvic floor muscles and cause urine to leak. Giving birth can also affect those same muscles. Symptoms of incontinence may persist even after delivery. Hormones, genetics and other lifestyle factors, like smoking, can also make it more likely that a woman will experience incontinence after childbirth. Doing regular Kegel exercises will strengthen the pelvic floor muscles and can help to prevent urinary incontinence after childbirth. We have many resources all about Kegels including how to do them and how often, exercise tips and more. We emphasized and strong encourage pelvic floor stimulation for those who encounter postpartum period

\section{Objective}

To describe and compare the effectiveness and complication rates of kegel exercise (active exercise) and electronic pelvic muscle stimulation with magnetic-field chair (passive exercise).

\section{Methods}

Preliminary results of a multicentre RCT are presented. Women were randomized to undergo Kegel exercise or Electronic pelvic muscle stimulation. A block-randomization procedure, stratified by centre, was performed. Allocation to trial group was carried out by a central computer system. Women with pure stress urinary incontinence or stress-predominant mixed urinary incontinence were eligible. Postpartum follow-up was performed at one, six and twelve months. Outcomes were classified as cured, improved or failed defined by combined objective and subjective criteria. The main outcome was the cure-improvement rate at 1-year. Sandvik's and ICIQ-SF questionnaires were completed before and 1-year after two different pelvic floor exercise. Patient global impression of improvement (PGI-I) questionnaire was also completed at 1-year. Complications are also reported. Outcomes were analysed in an intention-to-treat basis.

\section{Result}

Recruitment of participants was closed after reaching the calculated sample size $(n=282 ;$ participants actually recruited=288). Based on last data actualization, 126 women were allocated to Active and 127 to Passive. Both groups were similar regarding their initial characteristics. 143 women have completed 1-year follow-up. The cure-improvement rate in this cohort was 92.9\% and $94.5 \%$ in the Active and Passive groups respectively 
$(\mathrm{p}=0.74)$. Changes in questionnaires scores were also similar. Based on the PGI-I score, patients find themselves to be mostly very much better after kegel exercise with both passive electronic stimulation. Complications are claimed as muscle soreness and stinging pain for less than two weeks. More cases of persistent pain were observed in the Passive group ( $4.8 \%$ vs. $0 \%$; $\mathrm{p}=0.014$ ).

\section{Conclusion}

The interim data analysis of this RCT finds that passive exercise has similar effectiveness than Active exercise when used in Magnetic field chair. Complication rates are also similar; however, more cases of persistent pain are observed in the Passive group. All these observations should be corroborated with the final complete data analysis.

During pregnancy and after childbirth, many women experience at least some degree of involuntary urination, called urinary incontinence. Some women also experience bowel (fecal) incontinence, which is involuntary loss of fecal matter. Obstetric anal sphincter injury (OASIS), defined as a third or fourth degree perineal laceration, is a relatively rare but serious obstetric outcome and may result in severe maternal morbidity [1-4]. Many factors can contribute to postpartum incontinence, including the baby passing through the birth canal during delivery, the increased weight of the uterus during pregnancy, and the unique hormones produced in pregnancy [5].Genetics and lifestyle factors, such as smoking, also play a role in a woman's likelihood of developing incontinence after pregnancy. Women with a higher body mass index (BMI) during and after pregnancy have a higher chance of incontinence after childbirth. Women who delivered their child naturally have a $50 \%$ greater chance of developing incontinence after childbirth than women who had a Caesarean delivery [6]. Obstetric anal sphincter injuries are a significant risk to the maintenance of anal continence in both the short and long term. This risk can be significantly reduced by identifying the injury, reconstructing the sphincter complex and optimising recovery. First line treatments for incontinence depend on individual circumstances, but can include strengthening exercises (Kegels), bladder training, nerve modulation, pelvic floor therapy, electrical stimulation to improve pelvic floor muscle contraction, or a pessary [7]. If after childbirth symptoms have not resolved with first line treatments, surgery can be used to treat incontinence. Results of a recent extended study of prolapse surgery showed that in $60 \%$ of women, two common procedures failed within 5 years [2]. Nevertheless, more than half of those patients still reported better quality of life than before uterosacral ligament suspension (ULS) and sacrospinous ligament fixation (SSLF) [3]. A procedure was considered a failure if, after 5 years, the repaired tissue descended past the upper third of the vaginal canal [4]. In addition, if a patient felt a bothersome bulge or sensation of prolapse, another surgery was necessary, or a removable pessary was necessary to relive her symptoms, the procedure also was considered a failure. Pelvic surgeons should extend their postoperative care for these patients and should approach prolapse treatment as something to monitor long term [8].

The American College of Obstetricians and Gynecologists (ACOG) has released a revised Committee Opinion to emphasize the idea of the "fourth trimester" in an attempt to reduce maternal morbidity and mortality numbers [8,9]. Optimizing Postpartum Care" will be addressed since ACOG had previously recommended a comprehensive postpartum appointment be scheduled within the first 6 weeks after birth. According to ACOG, currently as many as $40 \%$ of women who give birth do not attend a postpartum visit [10]. Women are more likely to have incontinence if they also had leakage problems during pregnancy, particularly in the first or second trimester. Women who also had long deliveries or needed forceps during labor are also more likely to experience urinary leakage.

According to the National Institutes of Health, women who have a natural delivery are $50 \%$ more likely to experience incontinence than women who deliver by C-section [11]. Women with a high BMI, or those who retain pregnancy weight gain after the birth of their child(ren), are more likely to experience incontinence and pelvic organ prolapse (POP) after giving birth. Postpartum weight loss decreases the risk of urinary incontinence, even if other risk factors such as age and/or type of delivery method exist; therefore; we conducted kegel exercise with electronic magnetic filed chair coexisted can improve the post partum pelvic organ prolapse. one suggest those who delivered by vaginal birth doing so as soon as possible.

\section{References}

1. Leeman LM, Rogers RG (2012) Sex after childbirth: postpartum sexual function. Obstet Gynecol 119(3): 647-655.

2. Huebner M, Brucker SY, Tunn R, Naumann G, Reisenauer C, et al. (2017) Intrapartal pelvic floor protection: a pragmatic and interdisciplinary approach between obstetrics and urogynecology. Arch Gynecol Obstet 295(4): 795-798.

3. Christopher M, Benjamin F, Kaven B, Christmann-Schmid C, Haya N, et al. (2016) Surgery for women with anterior compartment prolapse. Cochrane Database Syst Rev 11(11): CD004014.

4. (2018) ACOG Committee Opinion No. 736: Optimizing Postpartum Care. Obstet Gynecol 131(5): e140-e150.

5. Tinius RA, Yoho K, Blankenship MM, Maples JM (2021) Postpartum Metabolism: How Does It Change from Pregnancy and What are the Potential Implications? Int J Womens Health 13: 591-599.

6. Mélanie Aubé (2017) Surgical Procedures for Treatment of Pelvic Organ Prolapse in Women, p. 1-16.

7. Nicita G (1998) A new operation for genitourinary prolapse. J Urol 160(3 Pt 1): 741-745.

8. Swift SE, Bent AE (2008) Basic evaluation of the incontinent female patient. In: Ostergard's urogynecology and pelvic floor dysfunction, 6. In: Bent AE, Cundiff GW, Swift SE (Eds.), Lippincott Williams and Wilkins, Philadelphia, p. 69.

9. Toglia MR (2008) Evaluation of colorectal dysfunction. In: Ostergard's urogynecology and pelvic floor dysfunction, 6. In: Bent AE, Cundiff GW, Swift SE (Eds.), Lippincott Williams \& Wilkins, Philadelphia, p.364. 
10. Jarvis SK, Hallam TK, Lujic S, Abbott JA, Vancaillie TG, et al. (2005) Perioperative physiotherapy improves outcomes for women undergoing incontinence and or prolapse surgery: results of a randomised controlled trial. Aust N Z J Obstet Gynaecol 45(4): 300-303.
11. European Commission Scientific Committee on Emerging and Newly Identified Health Risks. Opinion on the safety of surgical meshes used in urogynecological surgery.

\section{Your next submission with Juniper Publishers will reach you the below assets}

- Quality Editorial service

- Swift Peer Review

- Reprints availability

- E-prints Service

- Manuscript Podcast for convenient understanding

- Global attainment for your research

- Manuscript accessibility in different formats

( Pdf, E-pub, Full Tsext, Audio)

- Unceasing customer service

Track the below URL for one-step submission https://juniperpublishers.com/online-submission.php 